\title{
¿UNA PAZ FALLIDA? DIFICULTADES DE LA CONSTRUCCIÓN DE PAZ EN COLOMBIA TRAS EL ACUERDO CON LAS FARC-EP*
}

\section{A failed peace? Difficulties in the peacebuilding process in Colombia after the agreement with the FARC-EP}

\author{
JERÓNIMO RÍOS SIERRA \\ Universidad Complutense de Madrid \\ jeronimo.rios@ucm.es
}

Cómo citar/Citation

Ríos Sierra, J. (2020).

¿Una paz fallida? Dificultades de la construcción de paz

en Colombia tras el acuerdo con las FARC-EP.

Revista de Estudios Políticos, 190, 129-163.

doi: https://doi.org/10.18042/cepc/rep.190.05

\section{Resumen}

El siguiente trabajo tiene como principal objetivo reflexionar sobre al actual escenario de violencia que acontece en Colombia tras la firma del Acuerdo de Paz suscrito entre las FARC-EP y el Gobierno colombiano, en noviembre de 2016. Tras revisar la literatura existente sobre los riesgos y posibilidades que ofrece un acuerdo como éste en el campo disciplinar de la resolución de conflictos y la investigación para la paz, se contrasta la realidad estructural e institucional que presenta el Estado colombiano con las implicaciones de los compromisos adquiridos entre la extinta guerrilla y el gobierno de Juan Manuel Santos. Solo así es posible entender las contradicciones y dificultades que atraviesa el país y que muestran un escenario irresoluto de violencia en muchos lugares en donde, tras el Acuerdo, ésta parece experimentar un proceso de intensificación.

* Este trabajo ha sido resultado del proyecto posdoctoral 2018-T2/SOC-10508 y, asimismo, del proyecto PR65/19-22461, denominado "Discurso y expectativa sobre la paz territorial en Colombia". De este último es el investigador principal y ha sido financiado en la convocatoria de Proyectos de I+D para jóvenes doctores, resultado del marco del convenio plurianual entre la Administración de la Comunidad de Madrid y la Universidad Complutense de Madrid de 2019 


\title{
Palabras clave
}

Acuerdo de Paz; Colombia; construcción de paz; FARC-EP; violencia.

\begin{abstract}
The following work has as its main objective to reflect on the current scenario of violence that occurs in Colombia after the signing of the Peace Agreement signed between the FARC-EP and the Colombian Government, in November 2016. First, the paper reviews the existing literature on the risks and possibilities offered by an agreement like this one in the disciplinary field of conflict resolution and peace research. Later, the article contrasts the structural and institutional reality presented by the Colombian State with the implications of the commitments agreed between the extinct guerrilla and the government of Juan Manuel Santos. Only in this way is possible to understand the contradictions and difficulties that the country is going through. In this way, an irresolute scenario of violence is shown that, in many places, after the Agreement, seems to intensify
\end{abstract}

\section{Keywords}

Peace Agreement; Colombia; peace building; FARC-EP; violence. 


\section{SUMARIO}

I. INTRODUCCIÓN. II. MARCO TEÓRICO Y ESTADO DEL ARTE. III. LAS CONDICIONES ESTRUCTURALES DE LA VIOLENCIA FRENTE AL ACUERDO DE PAZ. IV. POSIBILIDADES Y DIFICULTADES DEL ACUERDO DE PAZ. V. ENTRE LA IMPLEMENTACIÓN DIFÍCIL Y LA VIOLENCIA QUE NO CESA: 1. La oportunidad de expansión para los grupos postparamilitares. 2. La recomposición del ELN tras el desarme de las FARC-EP. 3. Un EPL más allá del Catatumbo. 4. La herencia de las FARC-EP: entre la continuidad de la violencia y el retorno a la lucha armada. VI. CONCLUSiONeS. Biblografía. Informes relacionados con el Acuerdo de Paz.

\section{INTRODUCCIÓN}

El siguiente trabajo ${ }^{1}$ reflexiona sobre los principales desafíos que se presentan en Colombia en relación con la violencia armada, una vez transcurridos tres años y medio de la firma del Acuerdo de Paz con el principal grupo armado del país: las Fuerzas Armadas Revolucionarias de Colombia-Ejército del Pueblo (FARC-EP). Hablar de Colombia supone hacer referencia a uno de los tres conflictos más violentos de América Latina, junto con Guatemala y Perú. Si bien hunde sus raíces formales en 1964, cuando surgen por primera vez las Fuerzas Armadas Revolucionarias de Colombia ${ }^{2}$ y el Ejército de Liberación Nacional (ELN), el conflicto armado colombiano ha ido evolucionando de manera compleja. A la concurrencia de diferentes grupos guerrilleros, más de veinte, que comienzan su andadura tras la experiencia de la Revolución cubana, hay que añadir la emergencia del paramilitarismo a finales de los setenta e inicios de los ochenta, la unión de la cocaína a la violencia y el auge de los cárteles de la droga en los ochenta y una acuciante debilidad de un Estado apenas preocupado por engrosar su insuficiente dimensión militar. El resultado, tal y como reconocía hace unos años el Centro Nacional de Memoria Histórica (2013) es el siguiente: más de 220000 muertes, 25000

1 Se agrade sobremanera la calidad de los comentarios y sugerencias de los evaluadores.

2 Estas incluyen las siglas de Ejército del Pueblo a partir de la VII Conferencia Guerrillera de mayo de 1982. 
desaparecidos y 27000 secuestrados, y el mayor número de víctimas por desplazamiento forzado interno del mundo.

Por todo lo anterior, el Kroc Institute de la Universidad de Notre Dame (2016) reconocía que, por sus implicaciones, el Acuerdo con la hasta entonces guerrilla más longeva de América Latina es el más ambicioso y completo de los de 34 firmados en las últimas dos décadas. Sin embargo, y a pesar de esto, ¿cuál es la situación actual que atraviesa Colombia en la actualidad?, ¿hasta qué punto se han consolidado los compromisos adquiridos entre el Gobierno de Juan Manuel Santos y la guerrilla? Pareciera, a tenor de los informes más significativos que dan seguimiento de la situación en el país, que la realidad de violencia e inseguridad se ha acentuado preocupantemente en los últimos dos años (Mecanismo de Seguimiento de Naciones Unidas, 2020). Por ello, el siguiente trabajo parte de una pregunta claramente definida: ¿cuáles son los factores que han llevado a esta situación de recrudecimiento de la violencia tras la firma del Acuerdo de Paz con las FARC-EP?

La hipótesis de partida pasaría por considerar que, a pesar de la firma de un acuerdo entre los principales actores del conflicto, en el presente escenario de involución se aprecian tres elementos explicativos, claramente significativos: la violencia activa que involucra a otros grupos armados además de las FARC-EP; la violencia estructural heredada e irresoluta durante décadas, y el escaso nivel de desarrollo en la implementación del Acuerdo de Paz. Ello, en suma, confiere cierta vigencia a la hipótesis que Johan Galtung plantease en 1969 y por la cual la firma de un acuerdo de paz, entendido como "paz negativa», en sí, es la mera concepción de una paz que se entiende como ausencia de guerra. Para que esta sea superada de manera efectiva resulta imprescindible que se transformen los condicionantes estructurales, simbólicos y culturales, entre otros, que sostienen dicha guerra ("paz positiva»).

Así, tal y como se dará cuenta en las siguientes páginas, muchos de estos elementos no han sido superados tras el Acuerdo con las FARC-EP en Colombia, permitiendo la concurrencia de distintos conflictos armados que se relacionan entre sí de manera compleja. A saber: a) del Estado con el ELN; b) del Estado con el Ejército Popular de Liberación (EPL); c) del Estado con las estructuras postparamilitares; d) del Estado con las diferentes disidencias de las FARC-EP, y finalmente e) una situación de confrontación de todos contra todos.

El artículo se organiza en cuatro partes. Se inicia con la revisión teórica más significativa sobre el estudio de la violencia armada y su transformación a través de un acuerdo de paz. Se identifican cuáles son las explicaciones que ofrece la literatura académica para entender por qué se supera un conflicto armado o por qué, tras un acuerdo de paz, la violencia se recrudece. Una tarea que se extrapola al caso colombiano, integrándose en este debate teórico las aportaciones más significativas sobre el estudio de caso. 
Después se analizan las variables explicativas de la actual situación de empeoramiento de la violencia en Colombia. Es decir, se presentan las condiciones estructurales e institucionales del país sobre las cuales tiene lugar el proceso de construcción de paz actual y se identifican las variables de riesgo que influyen en los procesos de paz, en atención a la realidad colombiana. Seguidamente se relaciona todo lo anterior con los principales compromisos y acciones que prevé el Acuerdo de Paz con las FARC-EP, haciendo especial énfasis en sus principales dificultades e incumplimientos, los cuales inciden en el recrudecimiento de la violencia de los últimos ańos. Finalmente, y antes de las conclusiones que cierran el trabajo, se aborda como tercera variable explicativa el repunte de confrontación entre diferentes grupos armados y estructuras criminales tras la desmovilización de las FARC-EP, lo cual ha transformado las de por sí complejas relaciones entre guerrillas y grupos criminales frente al Estado.

Metodológicamente se trata de un trabajo exploratorio y analítico. Todavía puede ser pronto para trabajos que aborden cuestiones tales como el éxito o fracaso de la desmovilización, el proceso de reincorporación o la superación de la violencia, si bien se pueden apreciar tendencias o situaciones de riesgo que han de ser profundizadas con estudios posteriores y que en la actualidad apuntan a la posibilidad de que la colombiana termine siendo una paz fallida. Para la realización del trabajo se ha utilizado una ingente literatura gris, recientemente publicada en forma de informes. Asimismo, se hace uso de cifras y mapas de la violencia que fueron, muchos de ellos, facilitados exprofeso por el Observatorio de Derechos Humanos y Derecho Internacional Humanitario (ODHDIH), en su momento adscrito a la Vicepresidencia de la República.

\section{MARCO TEÓRICO Y ESTADO DEL ARTE}

Según Collier et al. (2003) es importante normalizar la reaparición de dinámicas de violencia armada tras el fin de un conflicto armado o una guerra civil. Tal y como viene investigando desde hace dos décadas la investigación para la paz y la resolución de conflictos, superar la violencia depende de cómo concurran factores varios como la violencia estructural, el despliegue de recursos, las brechas etnoculturales o el tipo de Gobierno responsable de asumir un escenario de reconstrucción posbélica.

Hegre y Nygard (2015) o Walter (2015) condicionan las posibilidades de retorno de la violencia a las capacidades institucionales del Estado o, como sostiene Geddes (1999), los "conjuntos de capacidades». Hatzell y Hoddie (2007) se centran en el tipo de Gobierno encargado de asumir la tarea de 
superación de la violencia —enfatizando en construir situaciones de poder compartido (power-sharing)—, mientras que hay quienes se focalizan en el despliegue de recursos y la inversión económica sobre los factores que alimentan la violencia (Collier, 2009).

Desde la perspectiva de la elección racional propuesta por Touval y Zartman (1985), y especialmente este último (Zartman, 2009), es posible entender que el sostenimiento de la paz tras un largo episodio de violencia depende, en buena medida, de los checks and balances que acompañan a la nueva situación (Kalyvas y Kocher, 2007). De este modo, si existe una situación de «doble estancamiento doloroso» ${ }^{3}$ (mutually hurting stalemate) es más probable que el proceso de diálogo de paz convenza a las partes sobre la necesidad de promover reformas estructurales. Situación que, como sugiere Przeworski (1991), ha de generar mayores beneficios que el proseguir con la lucha armada.

$\mathrm{Si}$ existe un despliegue de acciones en favor de la reincorporación de excombatientes a la vida civil, traducido en formación para el trabajo u oportunidades socioeconómicas, es más probable que se minimice el riesgo del retorno a la lucha armada (Nussio, 2018). Igualmente, desde la geografía política se advierte que cuando existen fracturas espaciales importantes (multiples sovereignties) que hayan alimentado conflictos internos durante un largo tiempo, si no se minimizan estas por medio de inversión, infraestructura o descentralización, es muy posible que la violencia prosiga tras un eventual acuerdo de paz (Saleyhan, 2009). Lo anterior conduce a investigaciones que directamente alertan sobre los mayores riesgos de un retorno a la lucha armada allí donde, lejos de una victoria militar, ha tenido lugar un proceso de paz negociado (Walter, 2002). No obstante, siempre resulta imprescindible disponer de unos mínimos de solidez institucional en cuanto a fuerzas militares, capacidades de la Administración pública y Estado de derecho (Hendrix, 2010).

Recurriendo a un concepto clave de la sociología histórica del Estado como es las fuentes de poder social (sources of social power), propuesto por Michael Mann (1986, 1993), los factores de disposición de recursos económicos, comunidades de legitimación y una capacidad militar fuerte en favor del grupo armado que se desmoviliza inciden en posibles retornos a la violencia en el caso de acontecer situaciones de incumplimiento o frustración de expectativas. Uno de esos elementos es la ocurrencia de un resultado electoral negativo del grupo que abandona las armas — con independencia de que, como sostienen Walter (2015) o Keels (2017), las elecciones contribuyan a reducir el riesgo del retorno de la violencia-. De otro lado, está la posible

3 Se entiende como la situación de un conflicto armado en el que su prolongación, dadas las circunstancias, resulta mutuamente desfavorable para las partes involucradas. 
continuidad de fuentes de financiación ilícita que influencian la no superación de la violencia (Mashike, 2007), u otras situaciones como la falta de acceso a la tierra (Collier, 1994), la exclusión social o la falta de oportunidades para los excombatientes (Hill et al., 2008).

También afectan a la implementación de un acuerdo de paz el grado de presencia de peacekeepers internacionales (Fortna, 2004), las fracturas étnicas existentes (Horowitz, 1985), los factores simbólicos asociados a una duración notable de la guerra (Findley y Rudloff, 2012) o la falta de legitimidad y respaldo social del grupo armado que se desmoviliza (Gibson, 2018) y sobre el cual suelen pesar tergiversaciones y prejuicios que infundados (Nussio, 2018). Asimismo, son destacables los grados de liderazgo concurrentes en la implementación de un proceso de paz (Conolly y Doyle, 2018), unido a otros factores como el grado de cohesión interna y (convicción) con el que se afronta el proceso de reincorporación del otrora grupo armado (Pearlman y Cunningham, 2012).

Tampoco se pueden obviar otros factores que impulsan o restringen el retorno a la lucha armada (driving and restraining forces), tal y como apuntan Kaplan y Nussio (2018). Es importante atender a las motivaciones personales y las condiciones estructurales e institucionales que reposan detrás de la reincidencia de excombatientes (Ríos et al., 2019). Además, están las inseguridades y la desprotección que alimentan lo que Kalyvas y Kocher (2007), entre otros, denominan como el "dilema de la seguridad» (security dilema), y que conecta con los tradicionales enemigos -institucionales o no- que están detrás de todo proceso de paz. Un fenómeno al cual Stedman (1997) se refirió hace algo más de dos décadas con el término de «saboteadores de la paz» (spoilers of peace). En suma, se aprecia un elenco de variables, en muchas ocasiones difícilmente operacionables, que aún hoy afrontan debates irresolutos frentes a las imprecisiones y complejidades metodológicas de un objeto de estudio como este, en continua transformación ${ }^{4}$ (Richards, 2018).

Específicamente en Colombia, si bien se han producido innumerables escritos sobre el Acuerdo de Paz entre el Gobierno colombiano y las FARC-EP, ni los trabajos académicos han sido tan numerosos ni han prestado tanta atención a la violencia en sus múltiples manifestaciones. Llama la atención que la reconocida publicación Colombia Internacional, editada por la Universidad de Los Andes, y que es una de las dos revistas académicas de obligada referencia para la ciencia política colombiana, únicamente haya publicado entre finales de 2016 y septiembre

4 No existen herramientas metodológicas que aborden la reincidencia de grupos guerrilleros o insurgencias. Las existentes son para población carcelaria o personas con psicopatologías. Véase: Historical Clinical Risk Management 20 (HRC-20), Violent Extremism Risk Assesment (VERA) o Extremist Risk Guidelines 22+ (ERG 22+). 
de 2019 cuatro trabajos académicos sobre un total de ochenta artículos distribuidos en doce números. Estos versan, en concreto, sobre el rol de las mujeres y su inclusión en el proceso de paz (Céspedes y Jaramillo, 2018), y las actitudes políticas de la ciudadanía colombiana en función de su proximidad a las dinámicas de violencia Ortiz (2017). Más tangencialmente se aborda la relación de la movilización social frente al Estado colombiano más allá de la agenda estricta que prevé el Acuerdo de Paz (Ciro, 2018), y las relaciones de la minería ilegal con la violencia armada durante la década pasada (Ortiz y Rettberg, 2018).

Esta circunstancia contrasta con el activismo académico de la otra revista colombiana de referencia, Análisis Político, la cual edita la Universidad Nacional de Colombia. En el mismo tiempo, de un total de siete números publicados cuatro de ellos tienen relación directa con el Acuerdo de Paz. Dicho de otro modo, de 68 artículos publicados entre finales de 2016 y septiembre de 2019, treinta versan sobre este particular objeto de estudio. Sin embargo, casi la mitad (dicisiete) de los trabajos se centran en la Comisión de la Verdad, la Jurisdicción Especial para la Paz y otros aspectos mayoritariamente relacionados con víctimas.

Cuatro aportaciones se focalizan en las miradas territoriales de la construcción de paz y otras cuatro reflexionan sobre los arreglos institucionales del Acuerdo, desde la perspectiva gubernamental. Tres lo hacen con miradas propias de las relaciones internacionales, y dos tendrían más que ver, aunque también tangencialmente, con contenidos afines a los que propone este trabajo. El primero de ellos, de Mouly et al. (2019), se centra en una experiencia exitosa de reincorporación de combatientes de las FARC-EP en el Carare (Santander) y Samaniego (Nariño). Mientras el segundo, de García Ruiz et al. (2018), analiza las políticas de seguridad sobre grupos armados reorganizados tras la desmovilización paramilitar de la década pasada.

Pareciera que es en publicaciones de fuera de Colombia en donde se aprecia un mayor interés académico por el Acuerdo de Paz con las FARC-EP. Genera un especial interés la dimensión territorial de la construcción de paz (Cairo et al., 2018; Ríos y Gago, 2018), y en buena medida muchos de los mismos temas que se proponen en Análisis Político. Es decir, la justicia transicional y la cuestión de las víctimas (López Martínez, 2019; Rodríguez y Niño, 2019); los enfoques de construcción de paz con perspectiva de género (Fernández Matos y González Martín, 2019; Anicharico et al., 2019), o los trabajos sobre medios de comunicación y análisis del discurso (Barreto et al., 2019; Viana, 2019). También destacan aportes relacionados con los retos institucionales de la implementación del Acuerdo (Guerra-Sua, 2019; Grasa, 2019); las demandas de la reincorporación de excombatientes a la vida civil (Oettler y Rettberg, 2019), y cuestiones más próximas a la afectación del Acuerdo de Paz con el comportamiento político y electoral (Ramírez, 2019). 
Lo referente a las dinámicas de la violencia en el escenario de implementación al Acuerdo de Paz resulta escasamente abordado, con la excepción de publicaciones como las de Salas et al. (2018), Ríos et al. (2019), Maher y Thompson (2019), Ballvé (2019) o Lemaitre y Restrepo (2019). Quizá, por esto último, los mayores aportes publicados hasta el momento parezcan reposar más bien en informes o dossiers de entidades como la Fundación Ideas para la Paz $(2018,2019)$, Indepaz $(2017,2018,2019)$, Fundación Paz y Reconciliación (2019, 2019b) o el mismo Kroc Institute (2017, 2019). Sin embargo, en muchas ocasiones con las limitaciones explicativas e interpretativas propias de este tipo de documentos.

\section{LAS CONDICIONES ESTRUCTURALES DE LA VIOLENCIA FRENTE AL ACUERDO DE PAZ}

La dimensión estructural tiene una gran capacidad explicativa a la hora de entender el escenario por el que transita tanto la difícil implementación del Acuerdo de Paz como la representación de la violencia en una geografía periférica y con evidentes carencias en lo que a indicadores socioeconómicos se refiere. Así, en el siguiente epígrafe se intentará problematizar la magnitud de dicha variable estructural, haciendo énfasis en aspectos tales como la desigualdad de ingresos, el negocio cocalero y la importante brecha centroperiferia que conecta directamente con la geografía de la violencia.

De acuerdo con lo planteado anteriormente, una situación como el Acuerdo de Paz en Colombia exige intervenir sobre la mayor parte de las condiciones estructurales e institucionales que han soportado el conflicto armado durante décadas. De hecho, en la discusión teórica previa se advierten una veintena de factores que concentran mayoritariamente la reflexión académica relacionada con la continuación/superación de la violencia armada tras un acuerdo de paz.

Como ha puesto de manifiesto una prolija literatura al respecto (Sánchez et al., 1987; Reyes, 1988; Ramírez, 1990), las condiciones estructurales de la violencia en Colombia han servido de importante acicate para la reproducción y mantenimiento de aquella. Tradicionalmente ha sido un país con importantísimas brechas territoriales, agudizadas por una reforma agraria que nunca llegó ${ }^{5}$ (LeGrand, 1988), una circunstancia que desemboca en el hecho

5 La Ley 200 de 1936 o ley de tierras fue el primer intento de varios infructuosos por consolidar un modelo de formalización de los derechos de acceso y explotación de la tierra, así como de derechos y garantías laborales. 
que Colombia tenga un coeficiente de Gini en la distribución de sus ingresos de 0.50 (CEPAL, 2018), y que resulta mayor en el caso de la distribución de la propiedad de la tierra, que se eleva a 0.86 (Ríos et al., 2019). Una realidad que, como también recoge el índice de pobreza multidimensional de 2019, hacen del país uno de los más desiguales del mundo.

Esto conecta con un Estado cuyas capacidades institucionales son endebles de cara a minimizar los factores de la violencia y disponer de un repertorio de recursos óptimo que dirigir tanto a las víctimas de la lucha armada como a los excombatientes que asumen el proceso de dejación de armas. La democracia local en Colombia cuando menos adolece de una importante debilidad. Se trata del segundo país más centralizado de América Latina, como evidencia la notable inelasticidad vertical de renta (Estupiñán, 2011). De este modo, de cada dólar que se recauda en el país, más del $80 \%$ es gestionado por el nivel central del Gobierno, mientras que el $20 \%$ restante se reparte, casi a partes iguales, entre el distrito capital de Bogotá, los 32 departamentos —que son las unidades administrativas subnacionales del nivel intermedio- y 1123 municipios ${ }^{6}$. Una realidad que explica que en el país existan regiones con niveles de desarrollo humano apenas incipiente, por lo general coincidentes con la dinámica de una violencia mayormente periférica (Ríos, 2017).

$\mathrm{Si}$ se toman por buenas las cifras recogidas por el ODHDIH, que permitió el acceso para realizar este trabajo a sus registros de violencia guerrillera acumulados entre 1990 y 20157 , es posible observar cómo hasta antes del Acuerdo de Paz con las FARC-EP existen dos enclaves predominantes de violencia guerrillera en Colombia. De una parte, el nororiente del país, fronterizo con Venezuela, y en particular en torno a los departamentos de Arauca y Norte de Santander, también con notable presencia de ELN. De otro, el sur y suroccidente, especialmente en los departamentos de Cauca, Nariño, Caquetá y Putumayo, y que durante algún tiempo alimentaron el corredor fronterizo ecuatoriano (Echandía y Cabrera, 2018; Salas et al., 2018). Antes del inicio de la negociación con las FARC-EP, en el año 2012, se llegaron a contabilizar hasta 824 acciones guerrilleras, de las cuales 499 se concentraban en estos seis departamentos. Algo similar sucedía con el ELN, sobre todo entre Arauca y Norte de Santander, en donde se llegaron a registrar 50 de las 71 acciones llevadas a cabo (ODHDIH, s.f.).

6 No conviene perder de vista que la superficie terrestre de Colombia equivale a $1142000 \mathrm{~km}^{2}$

7 Los datos del ODHDIH provienen de los boletines diarios del Departamento Administrativo de Seguridad para todo lo que concurre entre 1998 y 2010, y del Comando General de las Fuerzas Militares para lo acontecido entre 2011 y 2015. 
Mapa 1. Geografía de la violencia y presencia de cultivos cocaleros, 2016-2018

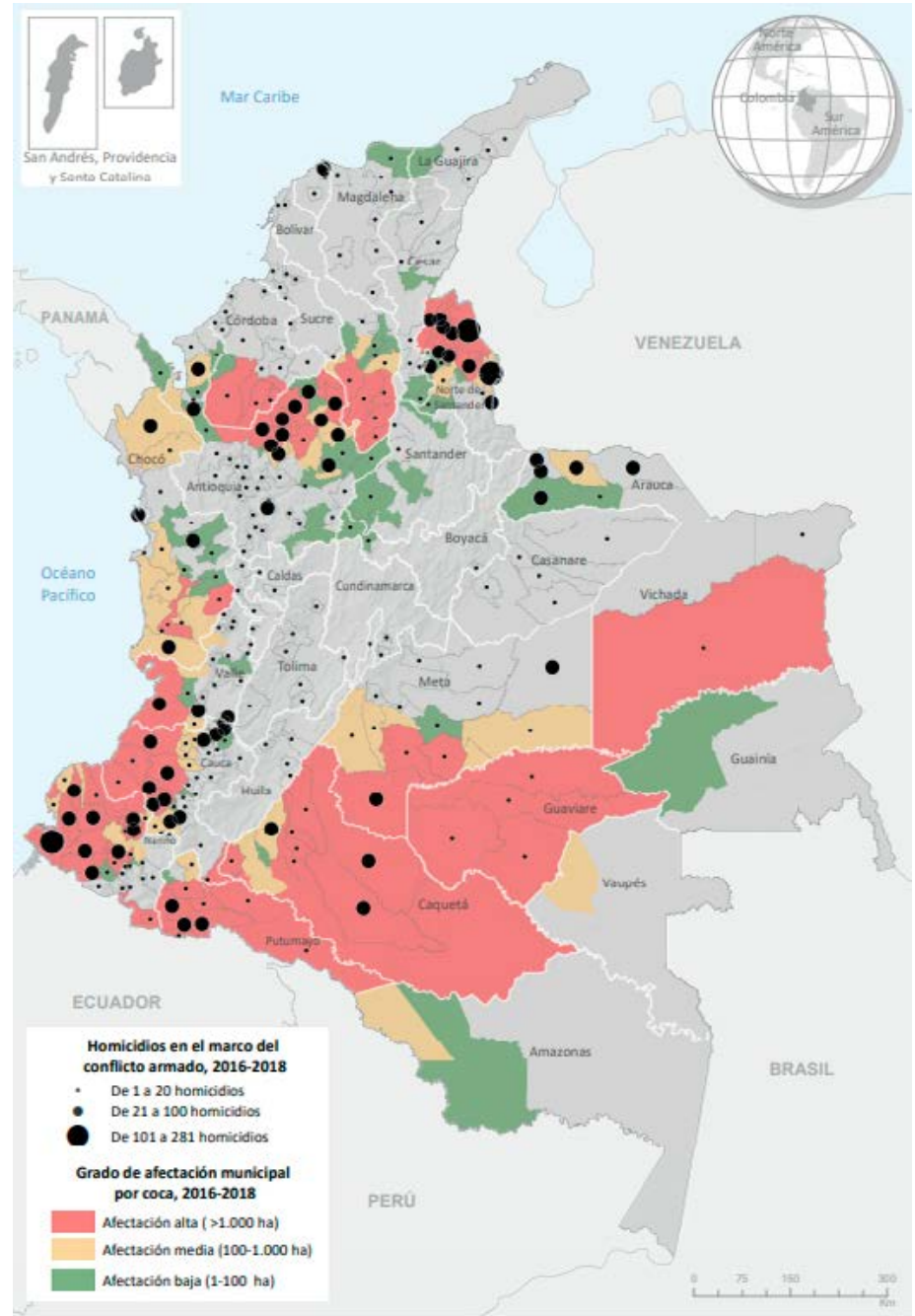

Fuente: UNODC (2019: 93).

Es decir, desde que inicia el Acuerdo de Paz y aún con posterioridad, los departamentos con mayor arraigo guerrillero son lugares en los que cabe apreciar, también, una correlación desfavorable de fuerzas para el Estado. En buena medida por la conjugación de factores que presentan esta geografía de la violencia, en donde se imbrica una realidad periférica geográfica y socioeconómica, junto a una condición fronteriza, una marcada impronta cocalera y una condición selvática y montañosa que dificulta los operativos militares 
(mapa 1). Esta afirmación puede quedar ilustrada si se observa de qué modo - y aunque en 2012 se llegan a contabilizar hasta 868 acciones del Ejército contra la guerrilla - en los seis departamentos mencionados con mayor presencia de FARC-EP y ELN el número de acciones armadas de la guerrilla supera ampliamente al proveniente del Estado (gráfico 1).

Gráfico 1. Número de acciones armadas en 2012 en los departamentos de mayor arraigo guerrillero

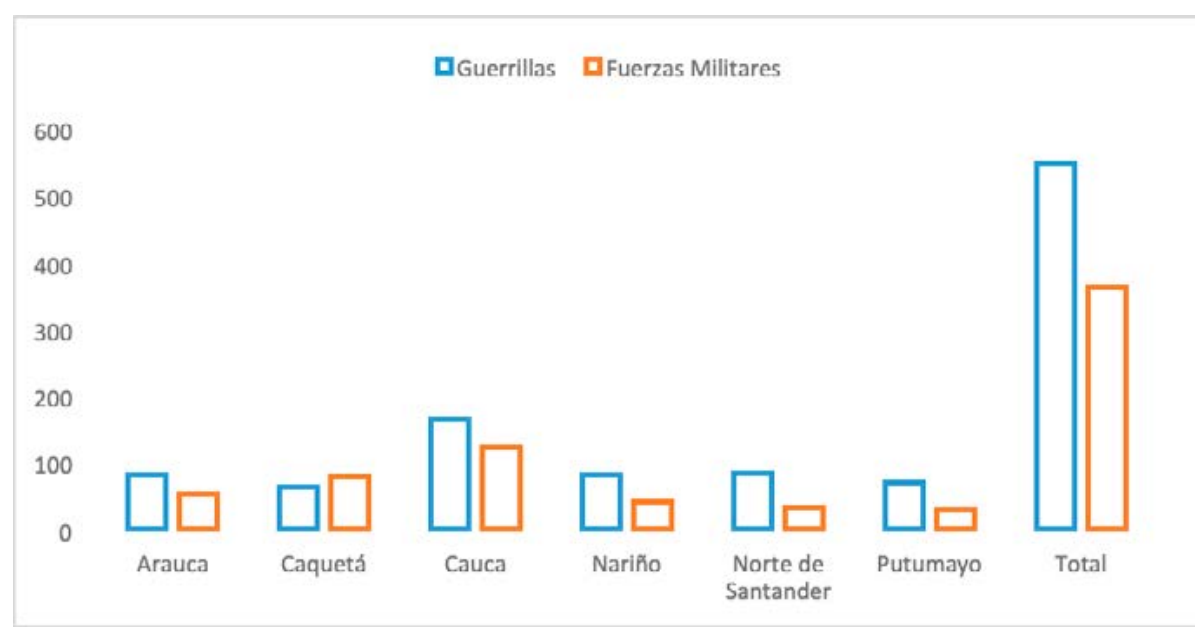

Fuente: elaboración propia con base en el ODHDIH (s. f.).

Otro factor clave es el negocio de los cultivos ilícitos en el que se encuentran inmersas las FARC-EP y el ELN desde hace décadas. Sus tradicionales enclaves territoriales representan los departamentos cocaleros por antonomasia del país. Tomando en consideración el reporte de acciones armadas de las guerrillas en 2015, y atendiendo a su situación territorial, casi el $75 \%$ de las 122 acciones guerrilleras y 60 municipios afectados por la violencia eran enclaves cocaleros (ODHDIH, s.f.). Igualmente, de acuerdo con UNODC (2019), la superficie cultivada con coca en 2018 equivale a 169000 ha, de las que $130795(77.3 \%)$ se condensan en los seis departamentos periféricos mencionados (especialmente Cauca, Caquetá, Nariño, Norte de Santander y Putumayo). En suma, un trinomio este de violencia, periferia y coca, que responde a una dinámica constante en los últimos años, tal y como recoge el gráfico 2. Ello, además, alertaría de la incapacidad del Estado colombiano para mitigar la violencia y reducir la superficie cultivada - la cual se ha cuadruplicado en cinco años-. 
Gráfico 2. Superficie cocalera con respecto a los departamentos de arraigo guerrillero (2013-2018)

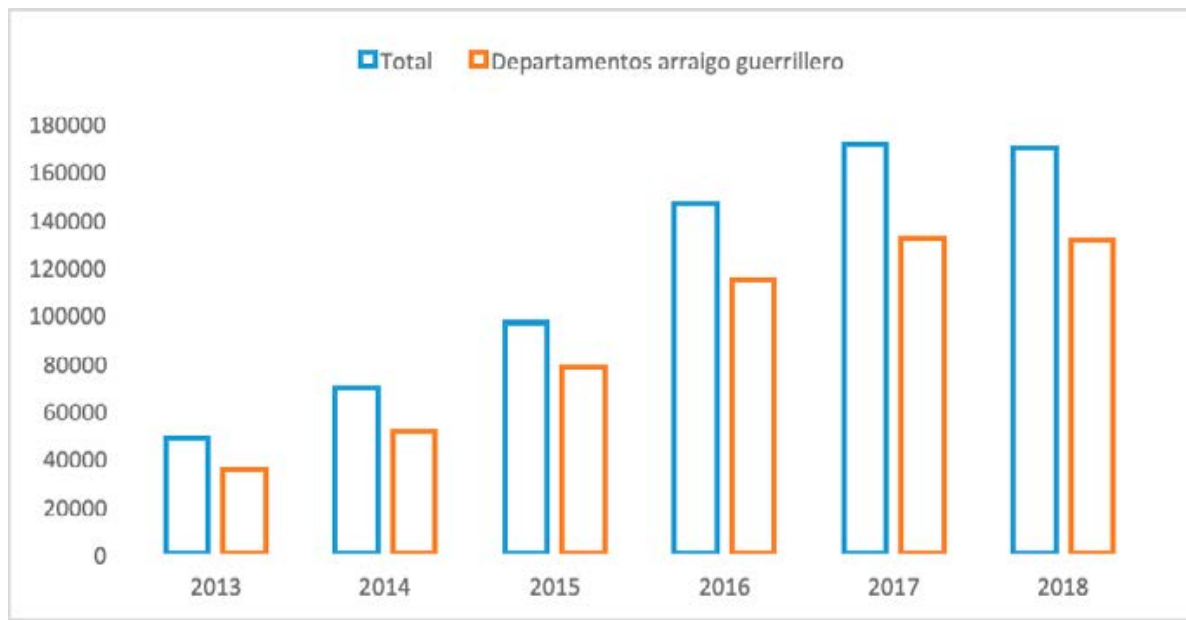

Fuente: elaboración propia con base en UNODC (2019).

Finalmente, y por cerrar los aspectos estructurales sobre los que se ha de construir el Acuerdo de Paz en Colombia, el resultado de inequidad social, falta de oportunidades, ausencia de descentralización y marcada violencia periférica tiene como resultado la imbricación entre violencia directa y violencia estructural (Galtung, 1969). Si se observa el año 2016, los seis departamentos referidos presentan condiciones socioeconómicas muy por debajo del promedio nacional. La mayoría de estos supera el promedio nacional de desigualdad en cuanto al coeficiente de Gini - Arauca (0.60), Putumayo (0.58), Cauca (0.52), Nariño (0.51) - y también el umbral de pobreza. Si bien el registro nacional de este indicador es de $28.7 \%$, este resulta ampliamente sobrepasado en Putumayo (66\%), Cauca (64\%), Caquetá (41\%), Norte de Santander (34\%) o Nariño $(30 \%)^{8}$. Por último, misma tendencia se advierte si lo que se atiende es el índice de necesidades básicas insatisfechas, analizado por el DANE en 2017, y que se recoge en el siguiente gráfico 3.

8 Si bien la tasa departamental de Arauca presenta un porcentaje de pobreza del $21 \%$, un año antes Naciones Unidas alertaba de que en las veredas en donde se condensa el activismo guerrillero este dato se eleva hasta un $93 \%$. 
Gráfico 3. Indice de necesidades básicas insatisfechas, 2016

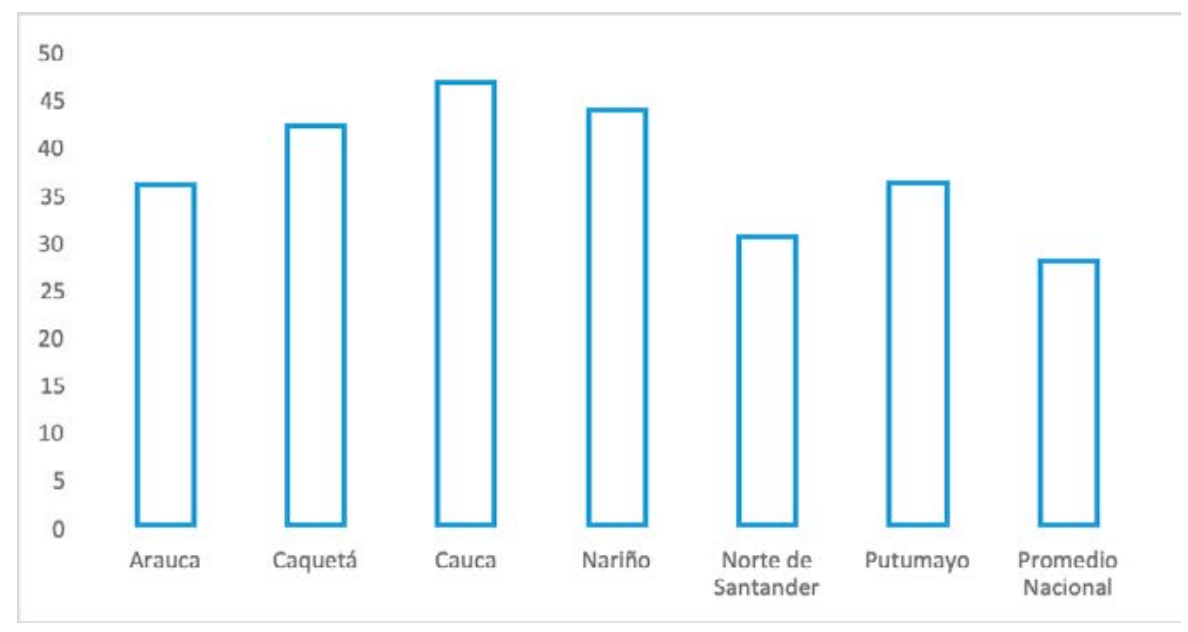

Fuente: elaboración propia con base en DANE (2016).

\section{POSIBILIDADES Y DIFICULTADES DEL ACUERDO DE PAZ}

Una segunda variable para tener en consideración, y que se analiza en las siguientes líneas, tiene que ver con las dificultades y limitaciones por las que transita el mencionado Acuerdo de Paz entre el Gobierno de Juan Manuel Santos y las FARC-EP. Un acuerdo de seis puntos que, no obstante, recogen compromisos que intervienen directamente sobre los elementos estructurales que sostuvieron la violencia durante décadas y que se exponen a continuación.

El primero de ellos, "Reforma rural integral», compromete a un total de diez millones de hectáreas para favorecer la titulación y explotación de tierras de aquellos enclaves que vivieron con mayor agudeza la violencia armada. Además de incentivar la inversión de recursos económicos, tejido productivo e infraestructura, se involucra a los municipios en el desarrollo de medidas políticas que, de manera eficaz, contribuyan a superar las condiciones de violencia estructural del orden local' .

En el segundo, "Participación política», se establecen los mecanismos más significativos que dotan a las extintas FARC-EP para poder llevar a cabo

9 Este tipo de herramienta es lo que se denomina Planes de Desarrollo con Enfoque Territorial —PDET-. 
la conformación de un partido político que se aleje de cualquier atisbo de reivindicación armada. Unido con aspectos del siguiente punto, se garantiza su presencia en el Congreso durante dos mandatos presidenciales, se fijan instrumentos de financiación y visibilidad mediática además de reformas institucionales con el propósito de visibilizar territorios que fueron especialmente afectados por la violencia.

En el tercer punto, "Fin del conflicto", se establecen los instrumentos para concluir el proceso de dejación y cese definitivo de la lucha armada de los algo más de 7100 combatientes que en agosto de 2016 conformaban las filas de las FARC-EP. Se fijan los protocolos y rutas por las que las FARC-EP han de transcurrir a efectos de desmovilizarse. Lo anterior, en un total de veintiséis zonas de transición en las que, en compañía del Estado, y con el apoyo de Naciones Unidas, se desarrollaron los primeros pasos hacia la entrega de armas. Unos primeros pasos que se acompañan de subsidios, ayudas y acciones formativas que brindan recursos y capacidades a los exguerrilleros que tornan hacia un proceso de reincorporación plena a la vida civil.

En el cuarto punto, denominado "Solución al problema de las drogas ilícitas», además de la colaboración de las extintas FARC-EP en el conocimiento de las rutas cocaleras que durante años fueron objeto de recursos para su financiación, se intenta diseñar una hoja de ruta para promover la sustitución paulatina y voluntaria de los cultivos cocaleros, sin renunciar, en última instancia, a la erradicación forzada. Conocedores, guerrilla y Gobierno, de la capacidad de recursos que genera la coca en Colombia, se piensa en escenarios y debates supranacionales con los que paliar el que puede ser el gran problema que soporta la violencia armada en el país tras décadas de confrontación (Pécaut, 2017).

El quinto de los puntos fijados en el Acuerdo, «Víctimas», establece todos los elementos para proteger los derechos que tienen las víctimas de un conflicto armado como este, de modo que se fijan los compromisos que blindan los derechos de justicia, verdad, reparación y no repetición. Se compromete la creación de una Comisión de la Verdad, una Unidad de Búsqueda para Personas Desparecidas por el Conflicto y un mecanismo de Jurisdicción Especial para la Paz que establezca las condiciones procesales y judiciales particulares de los excombatientes de las FARC-EP (sin transgredir el derecho internacional humanitario).

El Acuerdo finaliza con un sexto y definitivo punto, «Implementación, verificación y refrendación», que recoge los esquemas de seguimiento de la implementación, así como los actores de la comunidad internacional que han de acompañar dicha tarea; una responsabilidad que recae a nivel interno en la Comisión de Seguimiento, Impulso y Verificación (CSIVI), y a nivel externo en actores como Naciones Unidas, la Unión Europea o la Organización de 
Estados Iberoamericanos. Ello incorpora el apoyo en experiencias y la disposición de recursos provenientes de la cooperación internacional, además del monitoreo y las buenas prácticas con los que aspirar a una correcta implementación del Acuerdo.

Conviene señalar que muchas de las implicaciones y compromisos que fija el Acuerdo en la realidad se han visto lastrados por dificultades estructurales y resistencias institucionales del actual Gobierno, aparte de responsabilidades de otro orden provenientes de las extintas FARC-EP. Todas ellas son abordadas a continuación.

De manera más pormenorizada, y con vistas a generar mecanismos que impliquen una mayor inversión en los territorios más golpeados por el conflicto armado, el Acuerdo, en su primer punto, relativo a la reforma rural integral, identifica hasta un total de 170 municipios que se organizan en 16 zonas. Allí viven 6,6 millones de personas que son las destinatarias primeras de los recursos económicos con los que se aspirar a superar la situación de violencia. Este despliegue compromete un total de 79,6 billones de pesos colombianos (véase mapa 2), equivalentes aproximadamente a 22 millones de dólares, que deben desarrollarse en un lapso de veinte años, tal y como recoge el CONPES 3932 de 29 de junio de 2018. Empero, esta cifra está muy por debajo de los 129 billones (37 millones de dólares) a desarrollar en quince ańos como, inicialmente estaba previsto (Junguito et al., 2017), y que hoy día no ha iniciado.

Si bien estos instrumentos conocidos como Planes de Desarrollo con Enfoque Territorial (PDET) fueron diseñados en febrero de 2019 sobre la base de 33000 iniciativas centradas en salud, educación, convivencia, infraestructura, productividad, ordenamiento local y seguridad alimentaria, hasta el momento el comienzo de las inversiones se encuentra lastrado. Aparte de que llegaron casi con un año de retraso - pues se preveía que estuvieran cerrados en mayo de 2018 - hay que destacar la ausencia expresa de partidas presupuestarias en el Plan Nacional de Desarrollo con mención al Acuerdo de Paz con las FARC-EP. Igualmente, en la «hoja de ruta única» del Gobierno de Iván Duque, en su artículo 143, se señala que será el Gobierno quien defina las rutas de acción sobre las que desarrollar los PDET y, por extensión, la noción de desarrollo territorial. Algo que contraviene el sentido autónomo y «descentralizador» ${ }^{10}$ que prevé el Acuerdo, y a lo que debe sumarse el cambio de Gobierno municipal y departamental acontecido tras las elecciones de octubre de 2019.

10 Aunque Colombia es un país marcadamente (re)centralizado, el punto 1 del Acuerdo busca mitigar lo anterior, enfatizando la necesidad de construir la paz en clave territorial (Cairo et al., 2018). 


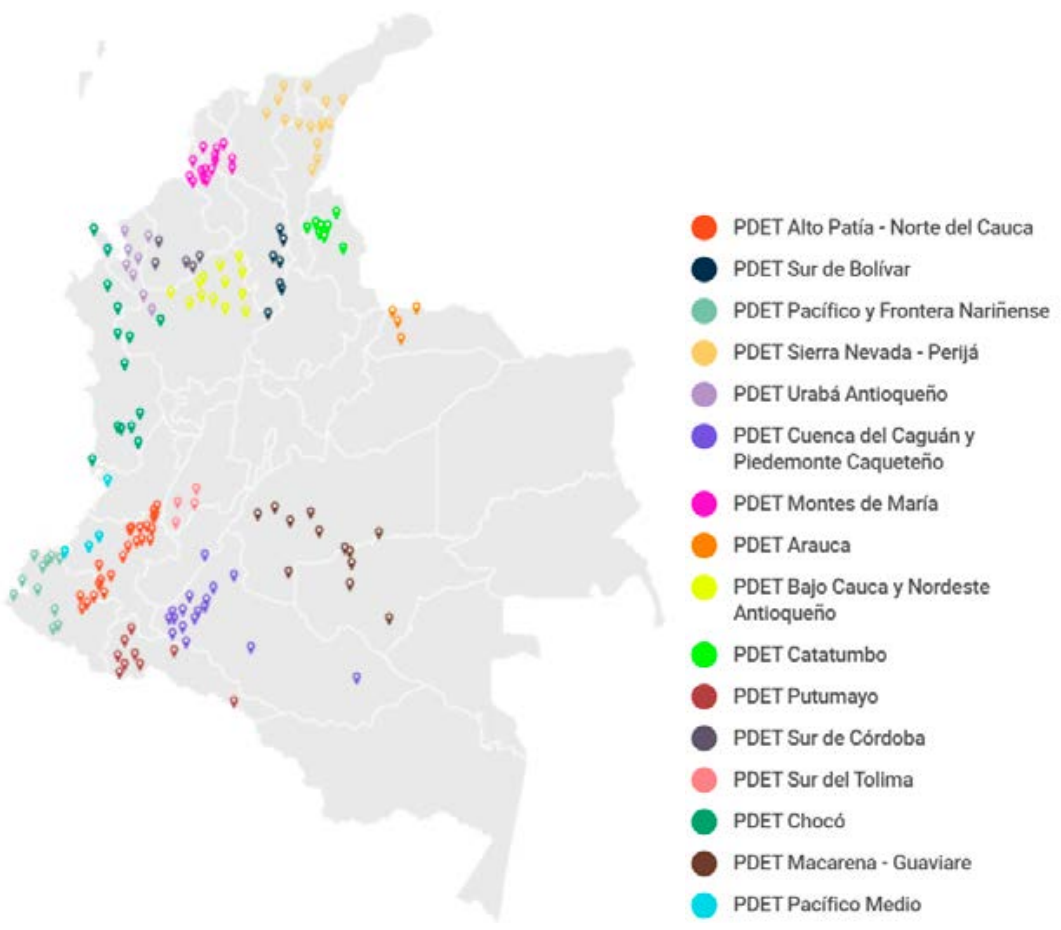

Fuente: Agencia de Renovación del Territorio (s.f.).

De otro lado, las elecciones legislativas y presidenciales de 2018 pusieron de manifiesto las dificultades políticas a las que se enfrentaban las extintas FARC-EP. El Acuerdo de Paz se había politizado desde antes de su firma, especialmente por parte de los opositores al mismo. A través de una campaña de desgaste, algunos de los principales nombres del conservatismo, como Álvaro Uribe, Marta Lucía Ramírez o Alejandro Ordóńez, trataron de demonizar aquel, tildándolo de promotor del "castrochavismo» y "narcoterrorismo" (Basset, 2018). Si al importante calado electoral conservador se ańaden otros elementos, como la concurrencia de un plebiscito (no vinculante) para decidir si la ciudadanía colombiana respaldaba o no el Acuerdo, la baja popularidad de Juan Manuel Santos como presidente, la escasa pedagogía que se hizo del referido Acuerdo o las elevadas reticencias que generaban las FARC-EP, es posible entender la negativa resultante en la consulta popular del 2 de octubre de 2016 como un preludio de la posterior victoria electoral del uribismo en los comicios legislativos y presidenciales de marzo y junio 2018. 
Aun con todo, el proceso de paz siguió adelante y cumplió con algunos de los compromisos adquiridos en aras de permitir el tránsito de las extintas FARC-EP hacia la vida política, tal y como se recoge en el segundo punto, «Participación política». Se otorgó personalidad jurídica al nuevo partido Fuerza Alternativa Revolucionaria del Común (FARC), y se reconoció una partida presupuestaria equivalente al $10 \%$ del límite de gastos fijado por el CNE (ubicado en 88413261314 pesos colombianos, equivalentes a 23,5 millones de dólares), además de la necesidad de una difusión mediática que, tal y como recogió el informe de seguimiento elaborado por la Organización de Estados Iberoamericanos (2018), finalmente no se materializó. Al contrario, hubo importantes episodios de violencia dirigida a los candidatos más significativos de las FARC-EP, lo cual contribuyó a que finalmente se desestimase la concurrencia electoral en los comicios presidenciales, para hacerlo únicamente en las elecciones legislativas. La FARC obtuvo un muy bajo resultado, equivalente a 52000 votos, que si bien no afecta a su representación concedida de cinco senadores y cinco congresistas, garantizada para las dos próximas legislaturas, se aleja muy sustancialmente de lo que la literatura académica define como power-sharing dentro de un proceso de rehabilitación posbélica.

Tampoco se produjo la reforma del Congreso para dar luz verde a la aprobación de dieciséis nuevas circunscripciones que por dos períodos legislativos debían representar directamente a los territorios más golpeados por la violencia. Aunque el Acuerdo de Paz evitaba expresamente que ningún partido, incluido la FARC, pudiera tener representación electoral en estos escenarios, se prodigó la idea desde los sectores opositores al Acuerdo de que eran concesiones ocultas a la extinta guerrilla. Así, en el momento de debatir y aprobar su creación, el partido Centro Democrático arguyó una falta de quorum en el Congreso que permitió relegar el asunto sine die de la agenda legislativa.

Si bien en el transcurso de las elecciones se contabilizaron veintisiete hechos de violencia según la Misión de Observación Electoral (2018), en ningún momento se dieron los mecanismos de protección relativos a proveer y proteger el ejercicio de la oposición política. En los últimos tres años, y como ilustra en parte el mapa 3, han sido asesinados más de setecientos líderes sociales y doscientos excombatientes de las FARC-EP, especialmente en los departamentos del suroccidente del país como Cauca o Nariño, además del departamento de Antioquia y la región del nororiente (Arauca y Norte de Santander) (Naciones Unidas, 2020; Indepaz, 2020). Una realidad que demanda un estudio mucho más detallado sobre los particulares condicionantes y las variables explicativas de este fenómeno en el nivel local, si bien parece entenderse que es la estructura criminal del Clan del Golfo y sus estructuras afines la principal amenaza de este tipo de violencia (Cabrera y Echandía, 2019). 
Mapa 3. Geografía de la violencia contra líderes sociales y exguerrilleros de las FARC-EP (2019)
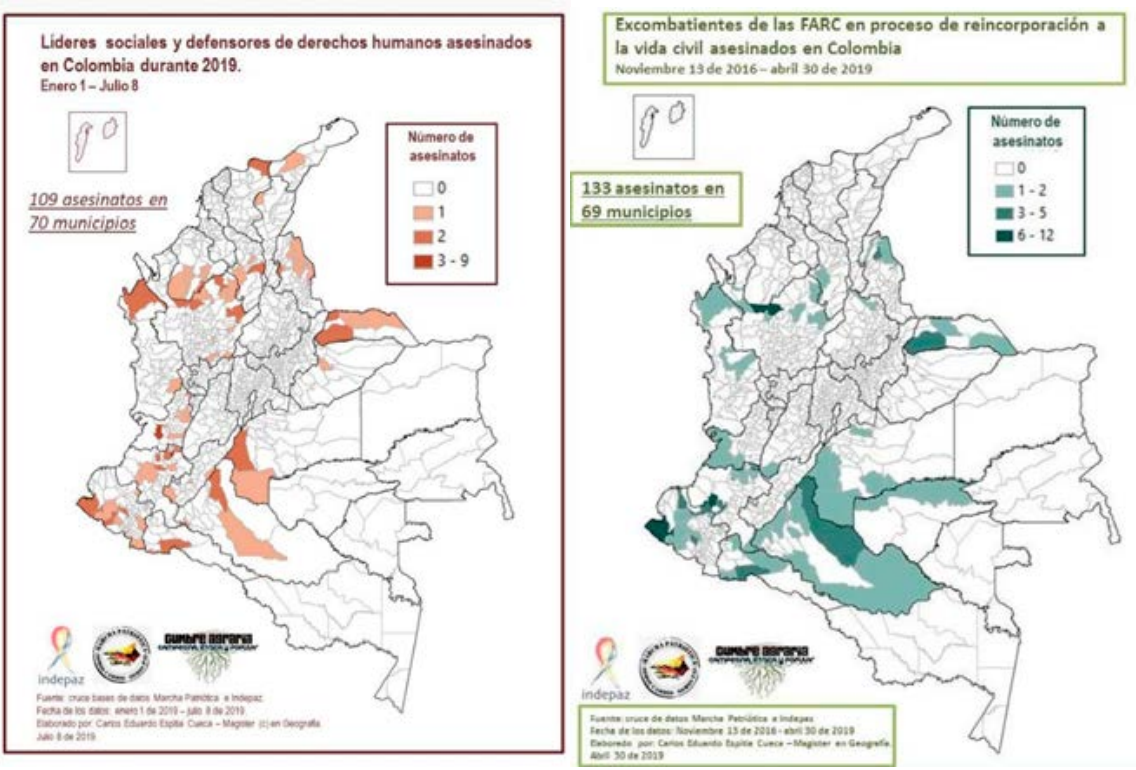

Fuente: Indepaz (2019).

Por otra parte, la dejación de armas generó en el interior de las FARC-EP importantes discusiones, producto de la desconfianza existente hacia el Estado. Sin embargo, desde el inicio estaba claro que se trataba de una condictio sine qua non para la viabilidad del Acuerdo. De esta forma, se negoció en el punto tercero, "Fin del conflicto", un proceso de desarme por medio de un esquema tripartito de identificación de rutas, zonas y mecanismos de seguimiento que garantizaban la entrega efectiva de las armas, así como la disposición del resto de armamento. Como se apuntaba, las FARC-EP, con el respaldo de Estado y Naciones Unidas, de forma paulatina se desmovilizaron íntegramente durante los primeros meses del Acuerdo de Paz. Los más de 7100 guerrilleros se concentraron en las veintiséis zonas habilitadas para ello, entregando no solo sus fusiles y armamento, sino igualmente revelando la posición de más de mil zulos (caletas) en donde guardaban su mayor arsenal bélico ${ }^{11}$. A cambio, el

11 Según ha reclamado el Gobierno en un debate producido en el Congreso en mayo de 2020, las FARC-EP distarían de haber entregado todo el material inicialmente reconocido. Así, no se reconoció la existencia de ochenta zulos y de los aproximadamente 11000 fusiles reconocidos finalmente se entregaron 8994. Además, según el uribismo, 
Estado debía iniciar el desembolso económico y las remuneraciones prometidas, acompañadas a su vez de la intervención que emocional y profesionalmente debía dirigir a los exguerrilleros hacia su plena reincorporación.

En inicio, la cohesión de las elites y la relación de estas con la estructura guerrillera - a la que se sumarían otros tanto milicianos y población carcelaria indultada por el Acuerdo y a la espera de su paso por la Jurisdicción Especial de $\mathrm{Paz}$ - hacía presagiar un correcto proceso de desarme. Se superó ampliamente el ratio de 0,76 armas/combatiente acontecido en Afganistán, y el de 0,6 de la desmovilización paramilitar, llegándose a las 1,3 armas por combatiente (Fundación Paz y Reconciliación, 2018). Sin embargo, según la Organización de Estados Iberoamericanos (2018) o la Fundación Ideas para la Paz (2018), las atenciones de primera urgencia en estos escenarios se hicieron, en muchas ocasiones, con importante retraso y hasta el punto de que en situaciones como en Nariño la financiación urgente corrió a cargo de las mismas FARC-EP.

Es decir, se llegó de alguna manera tarde a la implementación de las primeras medidas que exige la reincorporación suscrita en el Acuerdo, un riesgo importante y que repercute en la falta de incentivos para proseguir en los programas de reincorporación y alimentar actitudes negativas entre los excombatientes con respecto a lo que supone el Acuerdo de Paz. De hecho, recuérdese que un informe de diciembre de 2017 ya se alertaba que en menos de un año más de la mitad de los exguerrilleros había abandonado las zonas veredales fruto de su frustración y desengańo con el Acuerdo de Paz (Naciones Unidas, 2017).

A la vez que se daba este proceso, las fuerzas militares debían ocupar el vacío de poder territorial dejado por las FARC-EP, tal y como recogen los programas Plan Victoria y Corazón Verde. Tal situación nunca se dio y más bien, como se verá en el epígrafe siguiente, hubo un reacomodo de los actores involucrados en la geografía de la violencia acontecida tras la firma del Acuerdo. Esto generó que sin la presencia de las FARC-EP, pero tampoco de la policía ni del ejército, terceros grupos como el ELN, el EPL o disidencias de las FARC-EP y grupos criminales, pasaran a disputarse el poder local. Se trata de un factor que afecta al proceso de retorno de exguerrilleros frente a dinámicas de la violencia, ya sea por desengaño con el Acuerdo, por buscar esquemas de protección frente a posibles amenazas o por la influencia de una cooptación criminal que ofrece mayores réditos económicos que el proceso de reincorporación (Ríos et al., 2020).

existe un serio incumplimiento en el proceso de entrega de bienes de la extinta guerrilla, especialmente en lo que respecta a joyas, vehículos e inmuebles (Guerra, 2020) 
En todo caso, conviene normalizar el proceso de conformación de disidencias. Durante los primeros años que transcurren con posterioridad a un acuerdo de paz, lo habitual es que regresen a las armas entre el $8 \%$ y el 14\% de los exguerrilleros. Una cifra que, preocupantemente, ha sido superada poco después del primer año de implementación. Incluso, en 2019 varios informes - no sin un importante baile de cifras - estiman que el tamaño de los reincidentes en la violencia provenientes de las FARC-EP oscila entre el $17 \%$ (Crisis Group, 2019) y algo más del $30 \%$ (Ministerio de Defensa, 2019) ${ }^{12}$.

Todo este proceso ha sido escalonado y comienza a mediados de 2016, cuando la práctica totalidad del histórico Frente 1 de las FARC-EP, ubicado en el departamento de Guaviare, se desmarca del Acuerdo. Desde entonces se han advertido focos de disidencias de las FARC-EP en relación con los Frentes 18 y 36 de Ituango y Briceño; Frente 5 del Urabá antioqueño; Frente 57 del Urabá chocoano; Frente 10 de Arauca; Frente 58 en Córdoba; Frente 3 y 40 de Meta; Frente 29 de Narińo; Frente 60 de Cauca; Frente 59 de La Guajira; Frente 21 de Tolima; Frente 32 de Putumayo; Frente 33 del Catatumbo; Frente 34 de Chocó, y Frente 16 de Guanía y Vichada. Y además, las columnas móviles Teófilo Forero de Caquetá y Miller Perdomo en Valle del Cauca, o reducidas estructuras urbanas en Medellín, Cali, Barranquilla y Bogotá (véase mapa 4). Aunque sobre esto se volverá con posterioridad, algunas fuentes como la Fundación Paz y Reconciliación $(2018,2019,2019 b)$ estiman que las disidencias ascienden a una veintena de grupos que movilizan unos 1500 integrantes, muchos de ellos no excombatientes, sino personas de nueva reclusión.

Pareciera que el mejor elemento que conecta el retorno de la violencia por parte de las disidencias de las FARC-EP es el negocio del cultivo ilícito y en especial el narcotráfico. El grueso de estos grupos se encuentra en departamentos mayormente cocaleros, especialmente en el sur y suroccidente del país y en otras regiones como el Catatumbo, en Norte de Santander. De hecho, es significativo que sobre el total de 121 municipios con presencia de disidencias de las extintas FARC-EP, más del $80 \%$ sean enclaves cocalero y periféricos, una tesis que da por buena la tendencia de periferialización y narcotización de la violencia señalada por Ríos (2016), y que da continuidad a los trabajos de Echandía (2006) y Salas (2010).

Lo anterior se relaciona a su vez con la ya mencionada incapacidad del Estado colombiano por minimizar el impacto de las drogas ilícitas sobre la

12 En realidad, las cifras del Mecanismo de Seguimiento de Naciones Unidas muestran que más de un $95 \%$ de los exguerrilleros de las FARC-EP continúan actualmente en el proceso de reincorporación. En ocasiones se cofunde disidencia con nueva reclusión que, en realidad, es el fenómeno más generalizado. 
Mapa 4. Ubicación de las principales disidencias de las FARC-EP en 2018

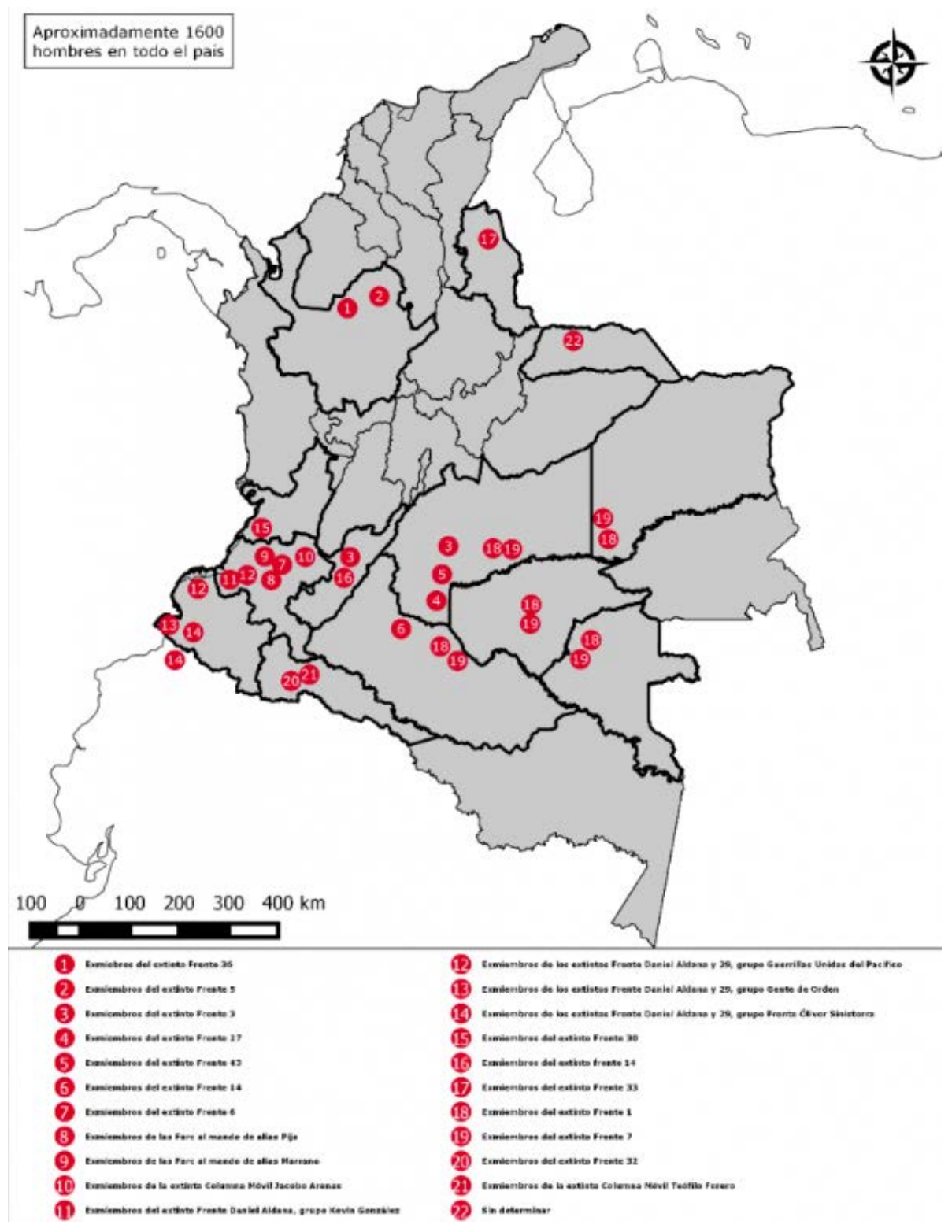

Fuente: Fundación Paz y Reconciliación (2019).

violencia, de manera que el cuarto punto del Acuerdo, «Solución al problema de las drogas ilícitas», apenas ha podido ser abordado. La sustitución de 
cultivos ha sido dejada de lado (Rodríguez Pinzón, 2017), y los esfuerzos se han centrado en medidas plenamente reactivas - véase el Decreto 1/10 de 2018-, como la intensificación de la erradicación forzada y el retorno de las aspersiones con glifosato ${ }^{13}$. Así se aprecia en atención al último informe de UNODC (2019), según el cual solo en 2018, desde la llegada de Iván Duque a la presidencia, se ha incrementado la erradicación forzada en más de un $10 \%$, alcanzando las 57000 ha y con visos de seguir creciendo.

Un último elemento importante es el relacionado con el componente de "Víctimas», recogido en el quinto punto, y que transita por un escenario de difícil cumplimiento. El presidente Iván Duque trató de objetar la ley habilitante de la Jurisdicción Especial para la Paz al entender que, a pesar de los compromisos adquiridos, dicho escenario de justicia transicional ofrecía inaceptables tratos de favor para parte de la guerrilla, especialmente mandos medios y comandancia de las FARC-EP. Tampoco se han integrado las partidas presupuestarias habilitantes en el Plan Nacional de Desarrollo y se confirmaba, en julio de 2019, que todo este componente, incluida la Comisión de la Verdad, vería reducida su financiación aproximadamente en un $30 \%$. Por todo ello, y de acuerdo con la mayoría de los informes, se trata del componente menos desarrollado de la implementación del Acuerdo de Paz (Fundación Paz y Reconciliación, 2019, 2019b; Organización de Estados Iberoamericanos, 2018; Indepaz, 2019).

A lo anterior se suma el escaso componente internacional que presenta el documento suscrito con las FARC-EP, fijado en el punto sexto del Acuerdo con el nombre de «Implementación, verificación y refrendación». No solo porque este punto se negoció de manera precipitada — en apenas unos díasmientras la extinta guerrilla, dadas las urgencias para finalizar, estaba centrada en otros puntos que consideraba más importantes. El papel clave de los peacekeepers proveniente de la comunidad internacional quedó relegado a un muy segundo plano, en coherencia con la noción de Estado fuerte y soberano que el mismo Juan Manuel Santos y su ministra de Exteriores, María Ángela Holguín, trataron de preservar en todo momento.

\section{ENTRE LA IMPLEMENTACIÓN DIFÍCIL Y LA VIOLENCIA QUE NO CESA}

Según lo planteado en estas páginas, el Acuerdo transita por una difícil tesitura, entre un proceso de implementación que mantiene todavía el efecto

13 Colombia es el único país del mundo que ha recurrido a este herbicida químico desaconsejado por la Organización Mundial de la Salud. 
luna de miel en cuanto a su cumplimiento y un mayoritario escenario irresoluto en favor de la continuidad de la violencia y de la consecución de una posible paz fallida para el país. En él confluyen, como se ha podido observar, carencias institucionales en la geografía de la violencia en Colombia, a las que se ańade una violencia especialmente dirigida hacia el colectivo de exguerrilleros y la confluencia de nuevas disidencias de las FARC-EP, favorecidas por la inalteración del negocio de la droga. También se suma una actitud de cierta desconfianza con el Acuerdo de Paz, visible en el rechazo social hacia los exguerrilleros que experimentan algunas zonas, junto a frustraciones con el proceso de reincorporación a la vida civil y un descrédito con los esquemas de justicia transicional que, de algún modo, influyen en nuevas movilizaciones hacia la violencia.

Quizás, todo lo anterior invite a considerar que más allá de las expectativas y bonanzas que recoge el Acuerdo, se está muy lejos de haber favorecido un escenario integral de transformación de la violencia y construcción de paz. Esto conecta con lo planteado al inicio de estas páginas: si no se interviene sobre las condiciones estructurales y simbólicas de la violencia, nada garantiza que un proceso de desarme suponga la superación plena de la misma (Galtung, 1969).

Todo lo contrario, las ventajas ofrecidas por un Estado con más territorio que soberanía alimenta que los diferentes grupos armados confronten entre sí por la disputa de los corredores estratégicos y los recursos de la violencia en el plano local, algo que afecta al imaginario colectivo erigido en torno a las posibilidades y beneficios del Acuerdo de Paz, y que transcurre sobre un escenario de confrontación irresoluta que alberga diferentes versiones y dimensiones en cuanto a su verdadero alcance y significado. Así, la variable de la violencia directa, representada a través de la intensificación de la misma por parte de diferentes grupos armados y estructuras criminales, termina por ser resultado de la violencia estrucutal, la deficitaria implementación del Acuerdo y una geografía del conflicto irresoluta. Estos tres elementos, por tanto, terminan por imbricarse, dando lugar a un escenario de mayor inseguridad y peores condiciones para la construcción de paz de lo esperado hace tres años y medio.

\section{LA OPORTUNIDAD DE EXPANSIÓN PARA LOS GRUPOS POSTPARAMILITARES}

El problema de los grupos postparamilitares comienza en 2008, cuando se inicia el proceso de rearme de estructuras, promovidas en muchas ocasiones por mandos medios y algunos comandandes de extintos bloques de las Autodefensas Unidas de Colombia (AUC). Desde hace años, producto de la mayor confrontación con las guerrillas, y también por el impacto de la fuerza pública, su capacidad operativa y su presencia territorial ha ido decreciendo lentamente. 
Tomando por buenas las cifras que ofrece Indepaz (2018), en 2011 el postparamilitarismo llega a su cénit en Colombia, cuando afecta a más de cuatrocientos municipios del país, mientras que en la actualidad se concentra en algo más de doscientos cincuenta y, particularmente, en cien de ellos pertenecientes a la Región Caribe, Antioquia y el litoral Pacífico. Si bien el Ministerio de Defensa (2017) en 2011 contabilizaba siete estructuras que integraban a algo más de 4100 efectivos, en la actualidad es posible encontrar un número próximo a la veintena de grupos y con una importante capacidad de reclutamiento y resiliencia, que les permite disponer de un grueso cercano a los 3000 efectivos.

De todos estos, el más poderoso son las Autodefensas Gaitanistas de Colombia (AGC), con cerca de 1800 integrantes, y que son herederas directas del extinto Bloque Élmer Cárdenas, comandando por don Mario. Denominado como Clan del Golfo por el Gobierno, mantiene un nexo de colaboración con el cártel de Sinaloa y ha sido objeto de importantes operativos, como la operación Agamenón I y II, que acabó con algunos de sus líderes más importantes (García Perilla y Herrera, 2020).

El resultado es que entre 2017 y 2019 se ha venido produciendo un proceso de atomización del fenómeno que ha terminado por alimentar facciones, fracturas y confrontaciones por el control de las rutas de cultivo, procesamiento y distribución de la coca, algo favorecido por el abandono de las FARC-EP de buena parte de estos territorios, lo que se evidencia en enfrentamientos producidos, por ejemplo, con Los Pachenca en los enclaves portuarios de Barranquilla y Cartagena. En el Bajo Cauca y el norte de Antioquia se disputan el control cocalero con Los Caparrapos y también con el ELN, en este caso por su interés sobre los proyectos minero-energéticos de la región (Fundación Ideas para la Paz, 2019).

Quedaría apuntar un proceso de expansión muy significativo en los Llanos Orientales, y en particular en los departamentos de Meta, Guaviare, Casanare y Vichada, en donde mayormente actuaba el Bloque Oriental de las FARC-EP. Lo mismo acontece con vistas al Pacífico, primero en torno a Nariño, clave para el otrora Frente 29 de las FARC-EP, y después en Chocó, en donde en todo 2018 y 2019 ha habido importantes enfrentamientos con el ELN por la explotación de madera y tráfico de drogas, algo que nuevamente responde a oportunismos coyunturales, como bien muestra la alianza entre guerrilla y AGC por la explotación aurífera de Río Quito.

\section{LA RECOMPOSICIÓN DEL ELN TRAS EL DESARME DE LAS FARC-EP}

Desde que las FARC-EP se demsovilizasen, el grupo que ha encontrado una mayor ventana de oportunidad para su recomposición ha sido el ELN. Primero 
porque definitivamente se erige como el actor hegemónico del nororiente del país, especialmente en Norte de Santander y Arauca. Se trata de dos enclaves de condición fronteriza con Venezuela; el primero con importantes réditos cocaleros, y el segundo con altas posibilidades extorsivas por el oleoducto Caño Limón-Coveñas, a lo que se suma en ambos casos el contrabando transfronterizo. De hecho, el ministro de Exteriores de Colombia presentó en septiembre de 2019, y ante la Organización de Estados Americanos, un documento en el que mostraba cómo el poderoso Frente de Guerra Oriental tenía asentamientos permanentes en suelo venezolano y llegaba a contar casi con 1500 efectivos en la zona. Si bien hay voces que elevan hasta 5000 los integrantes de esta guerrilla, más bien parece que están incluso por debajo de los 3000 efectivos, quedando por saber aún, por ejemplo, cuántos exintegrantes de las FARC-EP directamente han pasado a nutrir sus filas (Fundación Ideas para la Paz, 2020).

El desarme de las FARC-EP ha hecho que este ELN gane notoriedad en Antioquia, sur de Bolívar y en todo el litoral Pacífico, en donde la década pasada su presencia se reducía a Chocó y a una decena de municipios de Cauca y Nariño, en donde era predominante la posición de las FARC-EP. También se aprecia un intento por ganar relevancia en la costa Caribe, en donde atentaron contra un puesto de policía en febrero de 2017, y que se une a otras acciones transcurridas en 2018 y 2019.

Actualmente, sus mayores confrontaciones son en la región del Catatumbo, en Norte de Santander contra el EPL (Echandía y Cabrera, 2018), y en el Pacífico, contra cualquier lógica expansiva de grupos postparamilitares, tanto de los ya mencionados departamentos de Chocó y Narińo como del caso de Cauca, en donde en los últimos dos años se ha incrementado la presencia de pequeños grupos narcotraficantes.

\section{UN EPL MÁS ALLÁ DEL CATATUMBO}

El EPL es denominado vulgarmente como Los Pelusos, aunque se autorreconoce como continuador de la lucha insurgente iniciada por la primigenia guerrilla de 1967, ubicada en la región del Urabá antioqueño y chocoano, y una parte del departamento de Córdoba. Menos de doscientos guerrilleros se mantuvieron en armas tras el proceso desmovilizador de 1991, y a duras penas mantuvieron su capacidad operativa hasta la actualidad, y ello reubicando su posición territorial en la región del Catatumbo, gracias a los réditos del narcotráfico, aunque por ello mismo el Gobierno, al amparo de la Directiva 015 de 2016 del Ministerio de Defensa, le negó su condición de guerrilla y en la actualidad lo considera como un grupo narcotraficante.

También desde 2015, y en pleno proceso de reducción de las hostilidades con las FARC-EP, Los Pelusos ganaron notoriedad en algunos municipios 
como El Tarra, Convención, Tibú, Sardinata, Hacarí, La Playa, San Calixto, Teorama o El Carmen, en donde consiguieron afianzarse como un actor clave del negocio cocalero. Lo anterior terminó alimentando la confrontación con el Frente 33 de las FARC-EP y con el ELN. Solo gracias a su último gran líder, Megateo, la intensidad de la violencia se redujo, si bien este fue eliminado por el ejército a inicios de octubre de 2015.

$\mathrm{Su}$ fuerza ha ido creciendo en estos últimos tres años, y aunque hay un importante baile de cifras, todas las estimaciones coinciden en atribuir a Los Pelusos más de doscientos integrantes. No obstante, el heredero de Megateo, Luis Antonio Quiceno, Pácora, fue igualmente abatido en septiembre de 2019, dejando consigo un proceso de fragmentación y creciente criminalización que ha incrementado los niveles de violencia. Lo más importante es que, tras décadas, su presencia territorial ha conseguido ir más allá del Catatumbo y empieza a tener acciones en contextos que estaban bajo el control del Frente 59 de las FARC-EP, como en Curumaní, Chimichaguas y Pailitas, en el departamento de Cesar, y también en parte de la serranía del Perijá, clave en el corredor que une La Guajira con el estado venezolano de El Zulia. Finalmente, se ha registrado también presencia en el norte de Cauca, en municipios otrora controlados por las FARC-EP, como Corinto, Miranda, Suárez o Toribío, además de Jamundí, en Valle del Cauca - escenario este en donde también se recoge presencia y disputa territorial del ELN (Indepaz, 2018)—.

\section{LA HERENCIA DE LAS FARC-EP: ENTRE LA CONTINUIDAD DE LA VIOLENCIA Y EL RETORNO A LA LUCHA ARMADA}

Uno de los mayores desafíos del Acuerdo, producto de todo lo anterior, es la tendencia creciente de estructuras de las extintas FARC-EP que, o bien no se adscribieron al Acuerdo de Paz o bien retornaron a escenarios de violencia armada. Lo anterior, como se apuntaba previamente, en lugares de alto arraigo guerrillero y con altas posibilidades de nueva reclusión. Así, la Fundación Ideas para la Paz (2018) hablaba ya de 1500 efectivos involucrados en estos grupos, Indepaz (2018) lo eleva a 2500 integrantes y el Ministerio de Defensa aproxima la cifra a los 3000 miembros $^{14}$.

Sin embargo, todo este remanente heredero o relacionado con las FARC-EP exige de importantes precisiones, especialmente por la forma

14 En mayo de 2019 Reuters hizo público su acceso a documentos de la inteligencia del Ministerio de Defensa, en los que se alertaba que una tercera parte de los exguerrilleros desmovilizados habían vuelto a engrosar las filas de disidencias y otros grupos armados. Véase: https://bit.ly/3hQemPq 
heterogénea del proceso de rearme, los matices en la reivindicación del discurso de las FARC-EP como elemento de legitimación y una nueva práctica de la violencia en la que los criterios de alianzas y repertorios de acción se alejan mucho de la dirección unívoca que tenía lugar cuando existían las FARC-EP.

La primera gran disidencia con el Acuerdo de Paz fue el tradicional Frente 7 de las FARC-EP, comandado por Gentil Duarte, y activo en Guaviare, Meta, Caquetá y Putumayo, con entre trescientos y quinientos efectivos. Asimismo, y sobre enclaves compartidos, destaca el antiguo Frente 1, presente en Guaviare, Meta y Caquetá, pero con vocación territorial hacia el Amazonas. $\mathrm{Su}$ estructura cuenta entre doscientos y cuatrocientos integrantes y aspira a controlar las rutas de salida del narcotráfico hacia Brasil y Venezuela. Tanto el Frente 1 como el Frente 7 intentan controlar todo el corredor oriental, hasta el punto de que este último ha llegado a mantener alianzas con las AGC (Indepaz, 2018).

También en el escenario amazónico, el Frente Acacio Medina, con algo más de cien integrantes, se concentra entre Vichada y Guanía, colaborando en la cadena de procesamiento y distribución con el grupo local de Los Gorgojos y las AGC, si bien todos estos antiguos frentes de las FARC-EP, a su vez, han sufrido disidencias a lo largo del último año 2019.

Existen estructuras criminales herederas del Frente 29 y de la Columna Móvil Daniel Aldana activas en Nariño, en donde las cifras le otorgan entre ciento veinte y quinientos integrantes. Estos se han organizado últimamente en lo que se conoce como Guerrillas Unidas del Pacífico, conectadas con el cártel de Sinaloa y otras bandas criminales de Medellín, y cuyo foco de atención es el escenario cocalero de Tumaco y del triángulo del río Telembí, un esceario de altísima violencia por la disputa con el ELN, las AGC y otras estructuras herederas de la guerrilla, como el Frente Óliver Sinisterra, que dirigía el Guacho hasta diciembre de 2018, cuando fue eliminado ${ }^{15}$. Una estructura formada por entre trescientos y quinientos integrantes, y que confronta en Cauca con la Fuerza Unida del Pacífico, heredera del antiguo Frente 6 y que cuenta con cuatrocientos efectivos (Fundación Ideas para la Paz, 2019).

Lo cierto es que se cuentan por decenas las estructuras disidentes, aunque se aprecia un elemento clave. Los tres escenarios de mayor violencia heredera de las FARC-EP son Antioquia y Córdoba, toda la región sur y suroccidental - Cauca, Narińo, Putumayo y Caquetá - y el nororiente colombiano, especialmente Arauca y Norte de Santander. En ningún caso es posible identificar

15 El Guacho fue el responsable de matar a tres periodistas ecuatorianos de El Comercio que cubrían información sobre la violencia en la zona fronteriza en la que actuaba esta disidencia de las FARC-EP. 
un patrón único de colaboración, y son las particularidades locales, las relaciones entre liderazgos y las coyunturas del momento las que marcan el patrón interpretativo de la violencia. Una violencia en la que el ELN pareciera buscar ser el actor hegemónico frente a las AGC, de modo que son las disidencias y grupúsculos criminales los actores bisagra que median, promovidos por su urgencia por consolidar sus fuentes de financiación y proseguir en un escenario de violencia cada vez más atomizado, complejo e irresoluto.

\section{CONCLUSIONES}

Sobre la base de lo expuesto a lo largo de estas páginas, se ha problematizado la particular realidad que ofrece el Acuerdo de Paz suscrito entre el Gobierno colombiano y las FARC-EP en noviembre de 2016. Ello poniéndose en relación con los principales aspectos que repercuten negativamente a su proceso de implementación. De esta manera, la dimensión de una profunda violencia estructural irresoluta, unida a una violencia directa creciente y un deficitario proceso de cumplimiento del Acuerdo, desembocan en una situación preocupante. Así, de continuar con esta situación, el país puede aproximarse a un contexto de paz fallida que, definitivamente, no consiga cerrar las brechas de un conflicto armado cuya duración superó las cinco décadas.

Como acertadamente proponía Galtung, una cosa es finalizar un episodio de violencia y otra bien distinta es superarlo y transformarlo. Por esto, si bien se apuntaban las potenciales posibilidades que ofrece el caso de Colombia, se ha hecho especial énfasis en que la superación de debilidades, resistencias y dificultades son imprescindibles para transformar el escenario de violencia que tiene lugar en el país.

Hasta el momento, la literatura académica se centra más en otras cuestiones y tal vez es demasiado pronto como para llegar a trabajos de investigación concluyentes, con una impronta cuantitativa. Lejos de dicho propósito, este trabajo propone, como se recogía al inicio de mismo, una primera aproximación exploratoria y analítica que podrá contrastarse en un futuro no muy lejano. Quizás, una vez que haya transcurrido algo más de tiempo sea el momento de desarrollar otros trabajos que se centren en operacionalizar las variables intervinientes y facilitar análisis con mayor recorrido y proyección.

En cualquier caso, lo expuesto en estas páginas no renuncia a cierto peso argumentativo, en tanto que el Acuerdo de Paz en Colombia no solo tiene ante sí una muy difícil implementación, sino que todo invita a asumir escenarios inmediatos de mayor involución en el grado de consolidación de la paz y superación de la violencia armada. De cómo se den las circunstancias en el futuro próximo dependerá que se pueda analizar con más detalle las 
correlaciones entre violencia y cultivo cocalero, los factores explicativos del retorno a la lucha armada, el nivel de transformación o no de los escenarios locales de víctimas de la violencia, el grado de satisfacción de los exguerrilleros con el Acuerdo de Paz o el nivel de desempeño y compromiso del Gobierno con el proceso de implementación. Todos estos aspectos aseguran una prolija línea de investigación por profundizar en los próximos años.

Por el momento, queda destacar la dificultad estructural e institucional que presenta el Estado colombiano para poner en marcha un Acuerdo de Paz de estas características, las importantes resistencias e incumplimientos intervinientes y la importancia de una violencia redefinida que sigue siendo una de las urgencias irresolutas que afrontar en los próximos años. Todo para evitar que un Acuerdo ejemplar quede reducido a una paz fallida que tuvo todo a su disposición para poder cerrar exitosamente un episodio de violencia de más de medio siglo.

\section{Bibliografía}

Anicharico González, A. M., Martinez Ortega, H., Cerón Ruiz, C. C. y Rengifo Agudelo, K. (2019). Hacia una mirada feminista del rol de la mujer en el posconflicto colombiano. Journal of International Women's Studies, 20 (6), 75-93.

Ballvé, T. (2019). Narco-frontiers: A Spatial Framework for Drug-Fuelled Accumulation. Journal of Agrarian Change, 19 (2), 211-224. Disponible en: https://doi.org/10.1111/ joac. 12300 .

Barreto-Galeano, M. I., Medina-Arboleda, I. F., Zambrano-Hernández, S., Sabucedo-Cameselle, J. M., Blanco-Abarca, A. y Maurice Lair, É. (2019). Rhetoric, Political Ideology and the Peace Process in Colombia: A Twitter Analysis. Studies in Confict and Terrorism. En prensa.

Basset, Y. (2018). Claves del rechazo del plebiscito para la paz en Colombia. Estudios Políticos, 52, 241-265. Disponible en: https://doi.org/10.17533/udea.espo.n52a12.

Cairo, H. et al. (2018). Territorial Peace: The Emergence of a Concept in Colombia's Peace Negotiations. Geopolitics, 23(2), 464-488. Disponible en: https://doi.org/10.1080/146 50045.2018.1425110.

Cabrera, I. y Echandía, C. (2019). Retos institucionales y no institucionales para el partido Fuerza Alternativa Revolucionaria del Común (FARC) en las elecciones legislativas de 2018. Estudios Politicos, 56, 92-121. Disponible en: https://doi.org/10.17533/udea. espo.n56a05.

Centro Nacional de Memoria Histórica (2013). ;Basta Ya! Colombia: Memorias de guerra y dignidad. Bogotá: Centro Nacional de Memoria Histórica.

Céspedes, L. y Jaramillo, F. (2018). Peace without women does not go! Women's struggle for inclusion in Colombia's peace process with the FARC. Colombia Internacional, 94, 83-109. Disponible en: https://doi.org/10.7440/colombiaint94.2018.04.

Ciro, E. (2018). Ni guerra que nos mate, ni paz que nos oprima: incursión petrolera y defensa del agua durante las negociaciones y la firma de la paz en el sur de Colombia. Colombia Internacional, 93, 147-178. Disponible en: https://doi.org/10.7440/colombiaint93.2018.06. 
Collier, P. (1994). Demobilization and Insecurity: A Study in the Economics on the Transition from War to Peace. Journal of International Development, 6 (3), 343-351. Disponible en: https://doi.org/10.1002/jid.3380060308.

- (2009). Post-conflict recovery: How should strategies be distinctive? Journal of African Economies, 18(1), 99-131. Disponible en: https://doi.org/10.1093/jae/ejp006.

— et al. (2003). Breaking the Conflict Trap: Civil War and Development Policy. Washington DC: Banco Mundial. Disponible en: https://doi.org/10.1037/e504012013-001.

Conolly, E. y Doyle, J. (2018). Reflections on the Northern Ireland Conflict and Peace Process. Irish Studies in International Affairs, 26, 147-162.

Echandía, C. (2006). Dos décadas de escalamiento del conflicto armado en Colombia 19862006. Bogotá: Universidad Externado.

— y Cabrera, I. (2017). Madurez para la paz. Bogotá: Universidad Externado.

- (2018). La Fuerza Alternativa Revolucionaria del Común en las elecciones legislativas de 2018 (Catatumbo-Colombia). FORUM. Revista Departamento Ciencia Política, 16, 93-116. Disponible en: https://doi.org/10.15446/frdcp.n16.78174.

Estupiñán, L. (2011). Desequilibrios territoriales. Bogotá: Universidad del Rosario.

Fernández Matos, D. y González Martín, M. (2019). La paz sin las mujeres ¡no va! El proceso de paz colombiano desde la perspectiva de género. Revista CIDOB d'Afers Internacionals, 121, 113-133. Disponible en: https://doi.org/10.24241/rcai.2019.121.1.113.

Findley, M. y Rudloff, P. (2012). Combatant Fragmentation and the Dynamics of Civil Wars. British Journal of Political Science, 42 (4), 879-901. Disponible en: https://doi. org/10.1017/S0007123412000099.

Fortna, V. (2004). Does Peacekeeping Keep Peace? International Intervention and the Duration of Peace after Civil War. International Studies Quarterly, 48 (2), 269-292. Disponible en: https://doi.org/10.1111/j.0020-8833.2004.00301.x.

Galtung, J. (1969). Violence, Peace and Peace Research. Journal of Peace Research 6 (3), 167-191. Disponible en: https://doi.org/10.1177/002234336900600301.

García Perilla, J. y Herrera, A. (2020). Los spoilers del Acuerdo de Paz en Colombia: el caso del Clan del Golfo. Revista Colombiana de Ciencias Sociales, 11 (1), 204-233. Disponible en: https://doi.org/10.21501/22161201.2909.

García Ruiz, M. (2018). Políticas para combatir a los grupos armados posdesmovilización en los gobiernos de Álvaro Uribe Vélez y Juan Manuel Santos. Análisis Politico, 31 (92), 159-179. Disponible en: https://doi.org/10.15446/anpol.v31n92.71105.

Geddes, B. (1999). What Do Know about Democratization after Twenty Years? Annual Review of Political Science, 2 (1), 115-144. Disponible en: https://doi.org/10.1146/ annurev.polisci.2.1.115.

Gibson, S. (2018). Not as my Neighbour: How Misinformed Narratives Surrounding the FARC are Hindering the Social Reintegration of its Demobilizing Combatants. Journal of Peace and Social Justice, 12 (1), 25-37.

Grasa, R. (2019). Construir paz en Colombia: Reforma del sector de seguridad y violencia directa no política. Revista CIDOB d'Afers Internacionals, 121, 157-178. Disponible en: https://doi.org/10.24241/rcai.2019.121.1.157.

Guerra, R. (2020). Acuerdo Gobierno Santos-FARC: ¿quién no está cumpliendo? Ponencia presentada en el Congreso de la República. 18 de mayo de 2020. 
Guerra-Sua, A. (2019). Challenges for Peacebuilding and Citizenship Learning in Colombia. Magis, 11 (23), 169-186. Disponible en: https://doi.org/10.11144/Javeriana.m11-23. cpcl.

Hartzell, C. y Hoddie, M. (2007). Crafting Peace: Power sharing Institutions and the Negotiated Settlement of Civil Wars. College Park: Pennsylvania State University.

Hegre, H. y Nygård, H. (2015). Governance and Conflict Relapse. Journal of Conflict Resolution, 59 (6), 984-1016. Disponible en: https://doi.org/10.1177/0022002713520591.

Hendrix, C. (2010). Measuring State Capacity: Theoretical and Empirical Implications for the Study of Civil Conflict. Journal of Peace Research, 47 (3), 273-285. Disponible en: https://doi.org/10.1177/0022343310361838.

Hill, R., Taylor, G. y Temin, J. (2008). Would You Fight Again? Understanding Liberian Ex-Combatant Reintegration. Washington D.C.: United States Institute of Peace.

Horowitz, D. (1985). Ethnic Groups in Conflict. Berkeley: University of California Press.

Junguito, R., Perfetti, J. y Delgado, M. (2017). Acuerdo de paz: reforma rural, cultivos ilícitos, comunidades y costo fiscal. Bogotá: Fedesarrollo.

Kalyvas, S. y Kocher, M. (2007). How «Free» is Free Riding in Civil Wars? Violence, Insurgency, and the Collective Action Problem. World Politics, 59, 177-216. Disponible en: https://doi.org/10.1353/wp.2007.0023.

Kaplan, O. y Nussio, E. (2018). Explaining Recidivism of Ex-combatants in Colombia. Journal of Conflict Resolution, 62 (1), 64-93. Disponible en: https://doi. org/10.1177/0022002716644326.

Keels, E. (2017). Electoral Reforms and Peace Duration Following Negotiated Settlements. International Interactions, 44 (1), 33-58. Disponible en: https://doi.org/10.1080/03050 629.2017 .1296834$.

Legrand, C. (1988). Colonización y protesta campesina en Colombia, Bogotá: Centro.

Lemaitre, J. y Restrepo, E. (2019). Law and Violence in the Colombian Post-conflict: State-making in the Wake of the Peace Agreement. Revista de Estudios Sociales, 67, 2-16. Disponible en: https://doi.org/10.7440/res67.2019.01.

López Martínez, M. (2019). Colombia, saliendo del laberinto. El proceso de paz con las FARC-EP en claves de justicia transicional (2012-2016). Ayer, 115 (3), 335-350.

Maher, D. y Thompson, A. (2018). A Precarious Peace? The Threat of Paramilitary Violence to the Peace Process in Colombia. Third Word Quarterly, 39(11), 2142-2172. Disponible en: https://doi.org/10.1080/01436597.2018.1508992.

Mann, M. (1986). The Sources of Social Power. Vol. 1. Cambridge: Cambridge University Press. Disponible en: https://doi.org/10.1017/CBO9780511570896.

- (1993). The Sources of Social Power. Vol. 2. Cambridge: Cambridge University Press.

Mashike, L. (2007). Former Combatants Involvement in Crime and Crime Prevention. Research Report. Centre for the Study of Violence and Reconciliation. Sudáfrica.

Mouly, C., Hernández, E. y Giménez, J. (2019). Reintegración social de excombatientes en dos comunidades de paz en Colombia. Análisis Político, 32 (95), 3-22. Disponible en: https://doi.org/10.15446/anpol.v32n95.80822.

Nussio, E. (2018). Ex-combatants and Violence in Colombia: Are Yesterday's Villains Today's Principal Threat? Third World Thematics Journal, 3, 135-152. Disponible en: https://doi. org/10.1080/23802014.2018.1396911. 
Oettler, A. y Rettberg, A. (2019). Varieties of Reconciliation in Violent Contexts: Lessons from Colombia. Peacebuilding, 7 (3), 329-352. Disponible en: https://doi.org/10.1080 /21647259.2019.1617029.

Ortiz, J. (2017). Conflicting Approaches to Peacebuilding? Explaining Political Attitudes towards Armed Conflict Issues in Colombia through Ideas and Interests. Colombia Internacional, 89, 81-108. Disponible en: https://doi.org/10.7440/colombiaint89.2017.03.

Ortiz, J. y Rettberg, A. (2018). Minería de oro, conflicto y criminalidad en los albores del siglo xxI en Colombia: Perspectivas para el posconflicto colombiano. Colombia Internacional, 93, 17-63. Disponible en: https://doi.org/10.7440/colombiaint93.2018.02.

Pearlman, W. y Cunningham, K. (2012). Nonstate Actors, Fragmentation and Conflict Processes. Journal of Conflict Resolution, 56 (1), 3-15. Disponible en: https://doi. org/10.1177/0022002711429669.

Pécaut, D. (2017). En busca de la nación colombiana. Bogotá: Debate.

Przeworski, A. (1991). Democracy and the Market: Political and Economic Reforms in Eastern Europe and Latin America. Cambridge: Cambridge University Press. Disponible en: https://doi.org/10.1017/CBO9781139172493.

Ramírez, A. (2019). Análisis de la democracia participativa colombiana. A propósito del plebiscito por la paz de 2016. Revista Española de Derecho Constitucional, 115, 171-203. Disponible en: https://doi.org/10.18042/cepc/redc.115.06.

Ramírez, W. (1990). Estado, violencia y democracia. Bogotá: Universidad Nacional de Colombia.

Reyes, A. (1988). Conflictos agrarios y luchas armadas en la Colombia contemporánea: Una visión geográfica. Análisis Político, 5, 7-29.

Richards, J. (2018). High Risk or Low Risk: Screening for Violent Extremists in DDR Programmes. International Peacekeeping, 25 (3), 373-393. Disponible en: https://doi. org/10.1080/13533312.2018.1440177.

Ríos, J. (2017). Determinantes geográfico-políticos de la acción violenta guerrillera: un análisis de la concurrencia regional de guerrillas y paramilitares en el conflicto colombiano. Revista Española de Ciencia Politica, 44, 121-149. Disponible en: https://doi. org/10.21308/recp.44.05.

- y Gago, E. (2018). Realidades y desafíos de la paz territorial en Colombia. Papers. Revista de Sociología, 103 (2), 281-302. Disponible en: https://doi.org/10.5565/rev/ papers. 2361 .

— et al. (2019). Departamentos de frontera y violencia periférica. Revista Criminalidad, 61 (2), 113-132.

- (2020). Risk Assessment Analysis of Attacks on FARC Ex-Combatants: Towards a New Evaluation Model of Probability. Journal of Policing, Intelligence and Counter Terrorism, 15 (1), 44-63. Disponible en: https://doi.org/10.1080/18335330.2020.1727945.

Rodríguez, E. y Niño, W. (2019). Derechos sociales y justicia transicional: Experiencias internacionales y el caso colombiano. Revista Mexicana de Sociología, 64(235), 359-364. Disponible en: https://doi.org/10.22201/fcpys.2448492xe.2019.235.64051.

Rodríguez Pinzón, E. (2017). Internacionalización del conflicto, del acuerdo y del postacuerdo. Evolución, continuidades y ruptura de una estrategia. Análisis Político, (90), 194-208. Disponible en: https://doi.org/10.15446/anpol.v30n90.68307. 
Salas, L. (2010). Corredores y territorios del conflicto armado colombiano: una prioridad en la geopolítica de los actores armados. Perspectiva Geográfica, 15, 9-36

- Wolff, J. y Camelo, F. (2018). Dinámicas territoriales de la violencia y del conflicto armado antes y después del acuerdo de paz con las FARC-EP. Bogotá: Instituto Colombo-Alemán para la Paz.

Saleyhan, I. (2009). Rebels without Borders: State Boundaries, Transnational Opposition and Civil Conflict. Nueva York: Cornell University Press.

Sánchez, G. et al. (1987[2009]). Colombia: violencia y democracia: Comisión de Estudios para la Violencia. Bogotá: La Carreta.

Stedman, S. (1997). Spoiler Problem in Peace Processes. International Security, 22 (2), 5-53. Disponible en: https://doi.org/10.1162/isec.22.2.5.

Touval, S. y Zartman W. (1985). International Mediation in Theory and Practice. Boulder: Westview Press.

Viana, M. (2019). Reorganizando la violencia: la «historia de éxito» colombiana y los límites del discurso del posconflicto. Revista CIDOB d'Afers Internacionals, 121, 135-156. Disponible en: https://doi.org/10.24241/rcai.2019.121.1.135.

Walter, B. (2002). Committing to Peace: The Successful Settlements of Civil Wars. Princeton: Princeton University Press.

- (2015). Why Bad Governance Leads to Repeat Civil War. Journal of Conflict Resolution, 59 (7), 1242-1272. Disponible en: https://doi.org/10.1177/0022002714528006.

Zartman, W. (2009). The Timing of Peace Initiatives: Hurting Stalemate and Ripe Moment. Washington DC: United States Institute of Peace.

\section{Informes relacionados con el Acuerdo de Paz}

Comisión Económica para América Latina (CEPAL). (2019). Panorama Social de América Latina 2018. Santiago de Chile.

Consejo de Seguridad. (2017). Informe del secretario general sobre la Misión de Verificación de las Naciones Unidas en Colombia. Nueva York.

- (2018). Informe del secretario general sobre la Misión de Verificación de las Naciones Unidas en Colombia. Nueva York.

- (2019). Informe del secretario general sobre la Misión de Verificación de las Naciones Unidas en Colombia. Nueva York.

Crisis Group. (2019). The Missing Peace: Colombia's New Government and Last Guerrillas. Bogotá.

- (2019b). Calming the Restless Pacific: Violence and Crime on Colombia's Coast. Bogotá.

- (2019c). Containing the Border Fallout of Colombia's New Guerrilla Schism. Briefing, 40.

Fundación Ideas para la Paz. (2018). Siguiendo el conflicto. Bogotá.

- (2019). La fragilidad de la transición. La paz incompleta y la continuación de la confrontación armada. Bogotá.

- (2020). ¿Qué hacer con el ELN? Opciones ante una derrota militar lejana y un diálogo improbable.

Fundación Paz y Reconciliación. (2018). Grupos posFARC y la posible reactivación de la guerra. Bogotá. 
- (2019). Más sombras que luces. La seguridad en Colombia a un año de Iván Duque.

- (2019b). Terminó la guerra. El postconflicto está en riesgo. Un año del Acuerdo de Paz.

Instituto de Estudios para el Desarrollo y la Paz. (2017). El complejo paramilitar se transforma. Bogotá.

- (2018). Conflictos armados focalizados. Informe sobre grupos armados ilegales Colombia 2017-2018. Bogotá.

- (2019). Todos los nombres. Todos los rostros. Informe de derechos humanos sobre la situación de líderes y defensores de derechos humanos en los territorios. Bogotá.

— (2020). Paz al liderazgo social. http://www.indepaz.org.co/paz-al-liderazgo-social/

Kroc Institute for International Peace Studies. (2017). Informe sobre el estado efectivo de implementación del Acuerdo de Paz en Colombia. Bogotá.

- (2019). Informe 3. Hacia una paz de calidad en Colombia. Bogotá.

Ministerio de Defensa de Colombia. (2017). Oficio 86869. Actualización de cifras. Bogotá.

— (2019). Logros de la política de defensa y seguridad. Bogotá.

Misión de Observación Electoral. (2018). Informe de la reincorporación política de las FARCEP. Bogotá.

Misión de Verificación de Naciones Unidas. (2020). Reporte del secretario general.

Observatorio de Derechos Humanos y Derecho Internacional Humanitario (ODHDIH). (s.f.) Sintesis de la violencia y la confrontación armada en Colombia, 1998-2012 y 2015. Bogotá.

Organización de Estados Iberoamericanos. (2018). Informe técnico de acompañamiento a la implementación del Acuerdo Final. Bogotá.

Programa de Naciones Unidas para el Desarrollo. (PNUD). (2018). Human Development Indices and Indicators. Nueva York.

UNODC (United Nations Office on Drugs and Crime). (2019). Colombia. Monitoreo de cultivos de coca 2018. Viena. 